\title{
PEMBERDAYAAN MASYARAKAT DENGAN TEKNOLOGI SUMUR RESAPAN GUNA MENINGKATKAN KETERSEDIAAN AIR TANAH
}

\author{
Rhenny Ratnawati ${ }^{1}$, Indah Nurhayati ${ }^{2}$, Muhammad Al Kholif ${ }^{3}$, Moch. Shofwan ${ }^{4}$ \\ 1, 2,3,4 Program Studi Teknik Lingkungan, Fakultas Teknik Sipil dan Perencanaan \\ Universitas PGRI Adi Buana Surabaya \\ Email: ratnawati@unipasby.ac.id \\ ${ }^{4}$ Program Studi Perencanaan Wilayah dan Kota, Fakultas Teknik Sipil dan Perencanaan \\ Universitas PGRI Adi Buana Surabaya \\ Jl. Dukuh Menanggal XII Surabaya 60234
}

\begin{abstract}
Abstrak
Tujuan kegiatan KKN-PPM adalah menyadarkan masyarakat akan pentingnya melakukan pelestarian lingkungan melalui konservasi air tanah dan memberdayakan masyarakat Desa Kalanganyar untuk membangun sumur resapan air hujan guna membantu penyerapan air agar lebih optimal. Target luaran produk yang dihasilkan dalam program ini adalah: 1. Terbentuknya kader lingkungan devisi konservasi air tanah sebagai upaya keberlanjutan program, 2. Terbangunnya sumur resapan, dan 3. Keterampilan dalam merawat sumur resapan. Metoda pelaksanaan yang dilakukan adalah tahap persiapan, pembekalan dan pemberangkatan mahasiswa KKN-PPM, pembangunan teknologi tepat guna (TTG), tahap pelaksanaan, dan pendampingan kader lingkungan devisi konservasi air tanah. Hasil kegiatan KKN-PPM konservasi air tanah menggunakan sumur resapan di Desa Kalanganyar Kecamatan Sedati Kabupaten Sidoarjo Provinsi Jawa Timur adalah: 1. Masyarakat Desa Kalanganyar selama ini belum memanfaatkan air hujan pada musim penghujan yang menyebabkan limpasan air hujan menjadi banjir dan mengalami keterbatasan air pada saat musim kemarau, 2. Bertambahnya pengetahuan masyarakat Desa Kalanganyar tentang pelestarian lingkungan dan konservasi air tanah menggunakan sumur resapan, 3. Kegiatan KKN-PPM Desa Kalanganyar Kecamatan Sedati Kabupaten Sidoarjo memberikan percontohan berupa bangunan sumur resapan pada Desa Kalanganyar untuk dijadikan percontohan konservasi air tanah pada Desa Kalanganyar.
\end{abstract}

Kata Kunci: Konservasi Air Tanah, Pemberdayaan Masyarakat, Sumur Resapan

\begin{abstract}
The purpose of the KKN-PPM activity is to make people aware of the importance of environmental conservation through groundwater conservation and empowering the people of Kalanganyar Village to build rainwater infiltration wells to help optimize water absorption. The output targets of the products produced in this program are: 1. Establishment of environmental cadres in the division of groundwater conservation as an effort to sustain the program, 2. Establishment of infiltration wells, and 3. Skills in maintaining infiltration wells. The method of implementation carried out is the preparation, debriefing and departure of KKN-PPM students, the development of appropriate technology (TTG), the implementation phase, and the assistance of environmental cadres in the division of groundwater conservation. Conclusions from the KKN-PPM activities on groundwater conservation using infiltration wells in Kalanganyar Village, Sedati District, Sidoarjo Regency, East Java Province are: 1. The people of Kalanganyar Village have not used rainwater in the rainy season which caused rainwater runoff to flood and have limited water during the dry season, 2. Increasing knowledge of the people of Kalanganyar Village about environmental preservation and groundwater conservation using infiltration wells, 3. KKN-PPM Kalanganyar Village Sedati District Sidoarjo Regency provides a pilot in the form of infiltration wells in Kalanganyar Village to be used as a pilot for groundwater conservation in the village Kalanganyar.
\end{abstract}

Keywords: Community Empowerment, Groundwater Conservation, Infiltration Wells 


\section{PENDAHULUAN}

Desa Kalanganyar, Kecamatan Sedati, Kabupaten Sidoarjo, Provinsi Jawa Timur secara administratif pemerintahan terbagi menjadi $6 \mathrm{RW}$ dan $23 \mathrm{RW}$ dengan jumlah penduduk 5.705 jiwa dan luas wilayah 27,30 km2 (Badan Pusat Statistik Kabupaten Sidoarjo, 2018). Desa Kalanganyar berbatasan langsung dengan selat Madura dan sebagaian pantainya berupa hutan mangrove. Kondisi geografis Desa Kalanganyar dilewati oleh daerah aliran sungai yang digunakan untuk irigasi lahan tambak. Sebagian lahan lain berupa pertanian dengan jenis tanaman palawija terutama jagung. Potensi yang ada di Desa Kalanganyar terletak pada hasil perikanannya, dimana sebagian besar masyarakat bermata pencaharian sebagai nelayan dan petani tambak (Nurhayati dkk., 2016)

Desa Kalanganyar yang berbatasan dengan Selat Madura ini dekat dengan laut, maka berpotensi terjadinya intrusi air laut. Kondisi lingkungan di Desa Kalanganyar pada musim kemarau sering mengalami kesulitan mendapatkan air bersih karena kondisi sumur gali atau bor yang kering. Di sisi lain, pada saat musim penghujan sering terdapat genangan air atau bahkan banjir saat hujan dengan intensitas dan curah hujan tinggi. Di sekitar desa terdapat sungai yang dimanfaatkan oleh warga untuk mencukupi kebutuhan air bersih apabila air sumur mengalami keterbatasan.

Desa Kalanganyar sudah tersalurkan air dari jaringan Perusahaan Daerah Air Minum (PDAM) Kabupaten Sidoarjo, tetapi sebagian besar warganya masih memanfaatkan air sumur untuk kebutuhan air besih. Di sisi lain, kondisi air sungai yang ada tercemar akibat tumpukan sampah dan limbah pengolahan ikan yang dibuang begitu saja ke badan air penerima tanpa adanya pengolahan terlebih dahulu (Sutrisno dkk., 2018). Keterbatasan air bersih pada musim kemarau dikarenakan kurangnya ketersediaan air tanah. Salah satu teknologi untuk meningkatkan ketersediaan air tanah dan menanggulangi banjir adalah dengan sumur resapan.
Sumur resapan air hujan merupakan prasarana untuk menampung dan meresapkan air hujan ke dalam tanah (Badan Standardisasi Nasional, 2017). Eksploitasi air tanah yang semakin besar seiring dengan perubahan fungsi penggunaan lahan, khususnya alih fungsi lahan kehutanan merupakan faktor utama penyebab berkurangnya daerah resapan air. Adapun langkah-langkah yang perlu diperhatikan dalam pembuatan sumur resapan (Badan Standardisasi Nasional, 2017) adalah sebagai berikut:

1. Tentukan lahan untuk penempatan sumur.

2. Jarak minimum sumur resapan air hujan terhadap bangunan.

3. Pengukuran muka air tanah.

4. Penentuan angka permeabilitas tanah.

5. Perhitungan dimensi sumur.

Kegiatan ini tentunya membutuhkan partisipasi masyarakat demi terwujudnya pelestarian lingkungan dan lingkungan yang kondusif sehingga warga Desa Kalanganyar tidak perlu lagi memanfaatkan air sungai yang tercemar untuk kebutuhan air bersih terutama pada musim kemarau. Salah satu bentuk peran serta masyarakat adalah membentuk kader lingkungan yang khusus menangani konservasi air tanah tersebut. Kader lingkungan ini sebagai penggerak masyarakat dalam peningkatan ketersediaan air tanah melalui konservasi air tanah dengan teknologi sumur resapan (Lutjito dkk., 2016). Peran serta masyarakat dalam melakukan konservasi air tanah sangat diperlukan terutama dalam hal: 1) Masyarakat turut menjaga kelestarian lingkungan terutama dalam hal konservasi air tanah, 2) Secara tidak langsung masyarakat turut membantu program pemerintah dalam pembangunan yang berkelanjutan akan peningkatan ketersedian air tanah sehingga generasi yang lain dapat merasakan sumber daya air, dan 3) Dalam suatu organisasi masyarakat (RT/RW, BPD dan lain-lain) turut aktif dalam melaksanakan program penigkatan 
ketersedian air tanah dengan membuat sumur resapan dibeberapa titik.

Berdasarkan kondisi di atas, tujuan kegiatan KKN-PPM adalah menyadarkan masyarakat akan pentingnya melakukan pelestarian lingkungan melalui konservasi air tanah dan memberdayakan masyarakat Desa Kalanganyar untuk membangun sumur resapan air hujan guna membantu penyerapan air agar lebih optimal. Target luaran produk yang dihasilkan dalam program ini adalah: 1 . Terbentuknya kader lingkungan devisi konservasi air tanah sebagai upaya keberlanjutan program, 2. Terbangunnya sumur resapan, dan 3. Keterampilan dalam merawat sumur resapan. Melalui kegiatan kader lingkungan devisi konservasi air tanah dengan membangun sumur resapan diharapkan akan meningkatkan kesejahteraan warga karena warga tidak lagi mengeluarkan biaya tambahan untuk memompa air sungai yang dialirkan ke sumur warga apabila musim kemarau berkepanjangan. Selain itu, juga untuk menyadarkan masyarakat akan pentingnya pelestarian lingkungan.

\section{METODE PELAKSANAAN}

Metode pelaksanaan program KKN-PPM ini adalah sebagai berikut:

1. Kelompok sasaran program KKNPPM. Kelompok sasaran implementasi konservasi air menggunakan sumur resapan adalah anggota pengurus Lembaga Pemberdayaan Masyarakat Desa (LPMD), Badan Permusyawaratan Desa (BPD), padukuhan, seluruh ketua RW dan RT Desa Kalanganyar. Hal ini dimaksudkan agar para tokoh masyarakat ini dapat menyampaikan informasinya kepada warganya pada masing-masing wilayahnya sehingga secara keseluruhan dapat mencakup seluruh warga Desa Kalanganyar.

2. Tahap persiapan dalam kegiatan ini adalah pengurusan perijinan, sosialisasi jadwal, dan teknis pelaksanaan kepada kepala desa dan perangkatnya
3. Pembekalan dan pemberangkatan mahasiswa.

4. Pembangunan Teknologi Tepat Guna (TTG) berupa sumur resapan.

5. Langkah-langkah pelaksanaan kegiatan KKN-PPM adalah sebagai berikut:

a. Untuk menyadarkan masyarakat akan pentingnya pelestarian lingkungan untuk mencegah banjir dan konservasi air tanah melalui sistem sumur resapan. Metoda yang digunakan adalah sosialisasi dilakukan dengan cara pemaparan materi pada pengurus anggota pengurus LPMD, BPD, padukuhan, seluruh ketua RW dan RT Desa Kalanganyar disertai dengan media gambar dan alat peraga. Sementara pembuatan sumur peresapan air hujan yang baik dilakukan oleh warga yang berminat terutama para tukang batu.

b. Pembentukan kader lingkungan. Pembentukan ini dapat dilakukan melalui komunitas masyarakat yang ada di Desa Kalanganyar.

c. Pembuatan sumur resapan.

Alat yang digunakan untuk pembuatan sumur resapan adalah sebagai berikut: cangkul, linggis, cetok, sekrop, sedangkan bahan yang dibutuhkan adalah sebagai berikut: pasir, kerikil, semen, ijuk, besi, pipa PVC, tong plastik, bendrat. Cara kerja pembuatan sumur resapan adalah sebagai berikut:

c.1. Pembersihan lahan

c.2. Pengerukan lahan dengan panjang $\mathrm{x}$ lebar $\mathrm{x}$ kedalaman adalah 1,7 meter x 1,7 meter $x \quad 1,5$ meter.

c.3. Pemasangan bata dengan diberi jarak 5 $\mathrm{cm}$.

c.4. Permukaan sumur diberi ijuk dan kerikil. 


\author{
c.5. Cor tutup sumur \\ resapan. \\ c.6. Penyiapan bak filter. \\ c.7. Pemasangan pipa.
}

d. Pendampingan. Keberlanjutan program untuk kegiatan KKNPPM ini adalah secara mandiri warga Desa Kalanganyar mampu membuat dan menerapkan sumur resapan yang sudah diberikan pada saat tim melakukan sosialisasi serta mendesimenasikan teknologi di wilayah yang belum terjangkau saat pelaksanaan KKN-PPM.

\section{HASIL PEMBAHASAN}

Hasil yang dicapai dalam pelaksanaan KKN-PPM di Desa Kalanganyar Kecamatan Sedati Kabupaten Sidoarjo adalah sebagai berikut:

1. Sosialisasi kegiatan KKN-PPM kepada Kepala Desa Kalanganyar Kecamatan Sedati Kabupaten Sidoarjo. Kegiatan ini bertujuan memberikan informasi kepada pemerintahan desa bahwa akan dilaksanakannya kegiatan KKN-PPM yang melibatkan pemberdayaan masyarakat Desa Kalanganyar, mahasiswa KKN-PPM, dan tim pelaksana kegiatan KKN-PPM. Dalam kegiatan ini, tim bersamasama dengan perangkat desa menyusun teknis pelaksanaan dan jadwal kegiatan (Gambar 1). Perangkat desa juga mempersilahkan balai desa sebagai tempat kegiatan KKN-PPM.

2. Pembekalan mahasiswa. Pembekalan teori dan praktik kepada mahasiswa ini bertujuan untuk mempersiapkan mahasiswa untuk dapat memahami insfrastruktur serta kehidupan masyarakat Desa Kalanganyar (Gambar 2). Materi pembekalan terbagi 2 (dua), yaitu materi umum dan materi subtansi. Materi umum disajikan dalam bentuk teori meliputi: KKN-PPM sebagai salah satu wujud imlementasi tridharma perguruan tinggi, wawasan kebangsaan, etika dan tata karma di masyarakat, pemerintah desa. Materi subtantif diberikan secara teori dan praktik meliputi: pembuatan lubang resapan biopori, konservasi air dengan teknologi sumur resapan. Pembekalan KKN dilaksanakan pada tanggal 28 dan 29 Juli 2018 yang berlokasi di kampus Universitas PGRI Adi Buana Surabaya.

3. Pemberangkatan dan penerimaan mahasiswa. Pemberangkatan mahasiswa KKN PPM dilaksanakan secara melembaga oleh Wakil Rektor I Universitas PGRI Adi Buana Surabaya pada tanggal 1 Agustus 2018 di Lapangan Kampus II Universitas PGRI Adi Buana Surabaya (Gambar 3). Upacara pemberangkatan diikuti oleh Dekan, Kepala LPPM, DPL dan mahasiswa KKN PPM. Penerimaan mahasiswa KKN PPM dilakukan di Kantor Balai Desa Kalanganyar Kecamatan Sedati. Mahasiswa KKN PPM diserahkan oleh Wakil Rektor I dan diterima oleh Camat Sedati Kabupaten Sidoarjo. Upacara penerimaan mahasiswa KKN PPM melibatkan Wakil Rektor I, Kepala LPPM, Camat, Kapolsek, Danramil, kepala desa, perangkat desa, DPL, dan mahasiswa. Kegiatan KKN-PPM akan dilaksanakan dalam kurun waktu satu bulan, yaitu pada tanggal 1-31 Agustus 2018.

4. Sosialisasi tentang pentingnya konservasi air tanah menggunakan sumur resapan. Kegiatan ini bertujuan untuk memberikan kesadaran kepada masyarakat tentang pentingnya melestarikan lingkungan dan konservasi air. Sosialisasi dihadiri oleh kepala desa, perangkat desa, dan masyarakat Kalanganyar Kecamatan Sedati Kabupaten Sidoarjo yang terdiri atas perwakilan 
RT/RW dengan total 60 peserta pada tanggal 10 Agustus 2018 di Balai Desa Kalanganyar. Hasil yang diperoleh dari kegiatan ini adalah masyarakat memahami arti pentingnya konservasi air tanah, sehingga saat musim penghujan ketika sering kali terjadi banjir maka air tersebut dalam diresapkan menggunakan sumur resapan. Apabila musim kemarau tiba, dimana sering kali terjadi keterbatasan air maka air pada sumur resapan tersebut dapat dimanfaatkan (Gambar 4). Sumur resapan mampu memperkecil aliran permukaan sehingga dapat menghindari terjadinya genangan aliran permukaan secara berlebihan yang menyebabkan banjir (Yuliyanti dkk., 2017). Masyarakat juga lebih memahami dan mengetahui bahwa manfaat sumur resapan lainnya adalah juga dapat memperbaiki kondisi air tanah atau mendangkalkan permukaan air sumur. Diharapkan air hujan lebih banyak yang diserapkan ke dalam tanah menjadi air cadangan dalam tanah (Azwarman, 2015). Air yang tersimpan dalam tanah tersebut akan dimanfaatkan melalui sumur atau mata air. Peresapan air melalui sumur resapan ke dalam tanah sangat penting mengingat adanya perubahan tata guna tanah di permukaan bumi sebagai konsekuensi dari perkembangan penduduk dan perekonomian masyarakat. Dengan adanya perubahan tata guna tanah tersebut akan menurunkan kemampuan tanah untuk meresapkan air. Hal ini mengingat semakin banyaknya tanah yang tertutupi tembok, beton, aspal, dan bangunan lainnya yang tidak meresapkan air. Penurunan daya resap tanah terhadap air dapat juga terjadi karena hilangnya vegetasi penutup permukaan tanah (Iriani dkk., 2013).
5. Bantuan TTG berupa sumur resapan. Selama kurun waktu 2 minggu tim KKN-PPM Desa Kalanganyar Kecamatan Sedati Kabupaten Sidoarjo melakukan penentuan lokasi terkait dengan perizinan dengan pemerintah desa dan pemilik lahan yang akan dibangun sumur resapan. Melalui program ini, tim KKN-PPM Desa Kalanganyar telah membantu konservasi air tanah dengan TTG sumur resapan. Pembangunan sumur resapan dilakukan pada tanggal 2025 Agustus 2018. Tim KKN-PPM Desa Kalanganyar Kecamatan Sedati Kabupaten Sidoarjo mendapatkan kendala terkait penentuan lokasi. Akan tetapi segala perizinan bisa terselesaikan dengan baik. Dalam proses pelaksanaan pembuatan sumur resapan berjalan dengan baik. Respon warga desa kalanganyar terhadap progam ini sangat baik, sehingga percontohan sumur resapan ini dapat diaplikasikan oleh warga Desa Kalanganyar sebagai TTG untuk konservasi air tanah. Sumur resapan dibangun di rumah Bapak Ulum RT 08 Desa Kalanganyar dengan dimensi 1,5 meter $\mathrm{x}$ 1,5 meter x 1 meter (Gambar 5 dan 6).

6. Monitoring dan evaluasi (monev) internal dari Universitas PGRI Adi Buana Surabaya. Kegiatan monev internal bertujuan untuk memonitoring hasil yang sudah dicapai dari kegiatan KKN-PPM serta mengevaluasi kendala-kendala yang dihadapi dalam pelaksanaan KKN-PPM. Monev internal ini dilakukan oleh LPPM Universitas PGRI Adi Buana Surabaya, Dekan Fakultas Keguruan dan Ilmu Pendidikan Universitas PGRI Adi Buana Surabaya, dan didampingi oleh Kepala Desa Kalanganyar. Kegiatan monev internal dilaksanakan di Balai Desa Kalanganyar pada tanggal 23 Agustus 2018 (Gambar 7 dan 8). 
7. Penarikan mahasiswa KKN-PPM. Setelah seluruh kegiatan telah dilakukan oleh tim KKN-PPM dengan waktu yang telah ditentukan, maka penarikan mahasiswa dilaksanakan pada tanggal 31 Agustus 2018 (Gambar 9).

8. Pendampingan kader lingkungan devisi konservasi air tanah. Kegiatan ini bertujuan untuk meningkatkan peran serta masyarakat dalam melestarikan lingkungan dengan melakukan konservasi air tanah demi menyelamatkan ketersediaan air tanah. Para kader lingkungan diharapkan memiliki tanggung jawab untuk mengajak para tetangganya menjaga kelestarian lingkungan hidup di sekitar rumah masingmasing terutama masalah konservasi air tanah. Selain itu, berkewajiban untuk memberikan pengetahuan dan keterampilan tentang teknologi sumur resapan. Kader lingkungan dibentuk dengan membentuk beberapa kelompok seperti kader pelestarian lingkungan dan konservasi air tanah. Kader ini dibentuk dengan keanggotaan sebanyak 7 orang yang diketuai oleh 1 orang.

9. Monev keberhasilan program kegiatan secara eksternal. Monev eksternal dilakukan oleh DRPM Kemenristek Dikti pada tanggal 22 Oktober 2018 di kampus UNESA Lidah Wetan Surabaya. (Gambar 10).

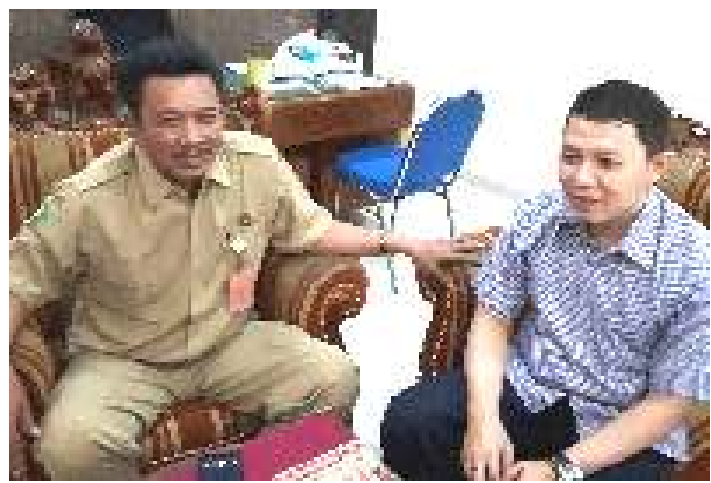

Gambar 1. Sosialisasi Kegiatan KKN-PPM kepada Kepala Desa Kalanganyar

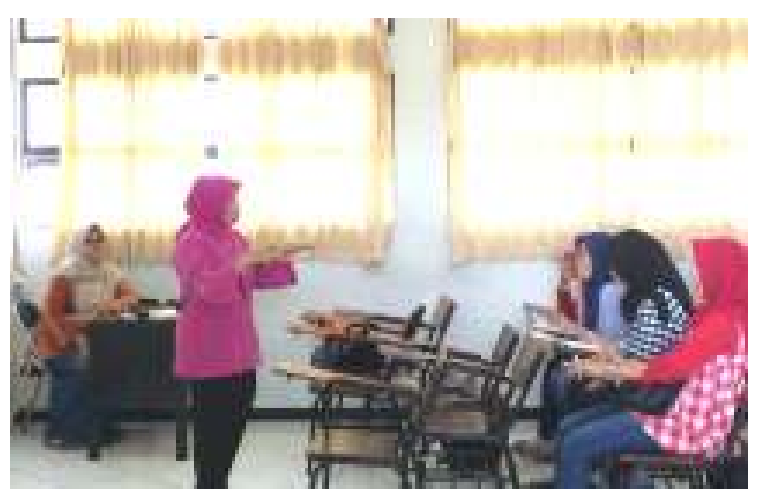

Gambar 2. Pembekalan Teori Konservasi Air Tanah kepada Mahasiswa KKN-PPM

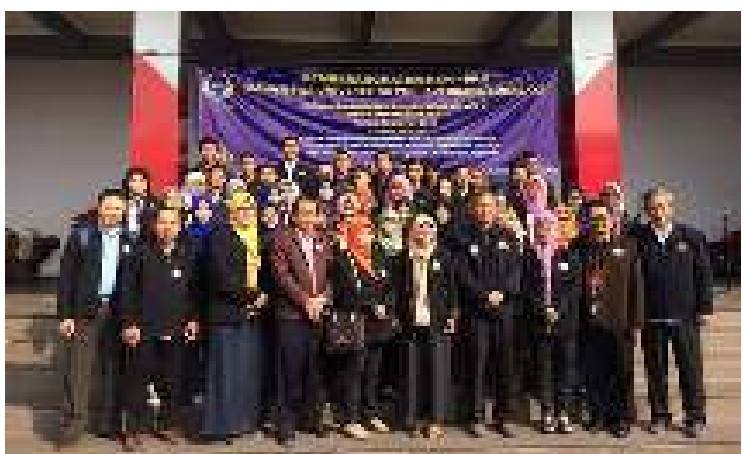

Gambar 3. Pemberangkatan Mahasiswa KKN-PPM

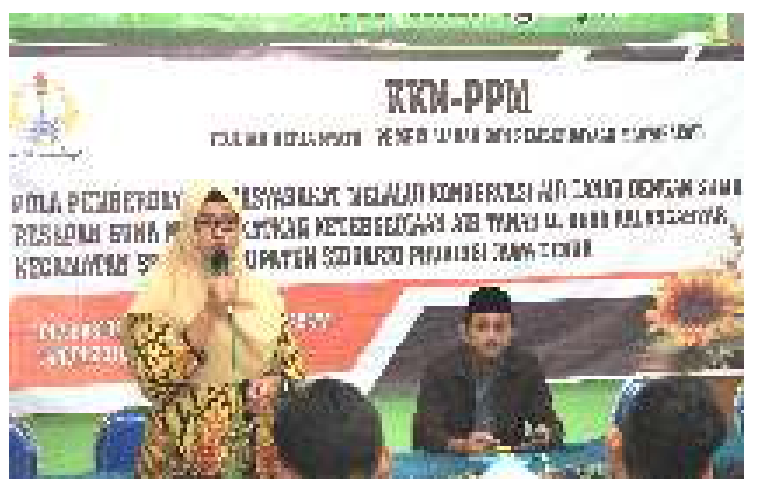

Gambar 4. Sosialisasi Konservasi Air Tanah Menggunakan Sumur Resapan 


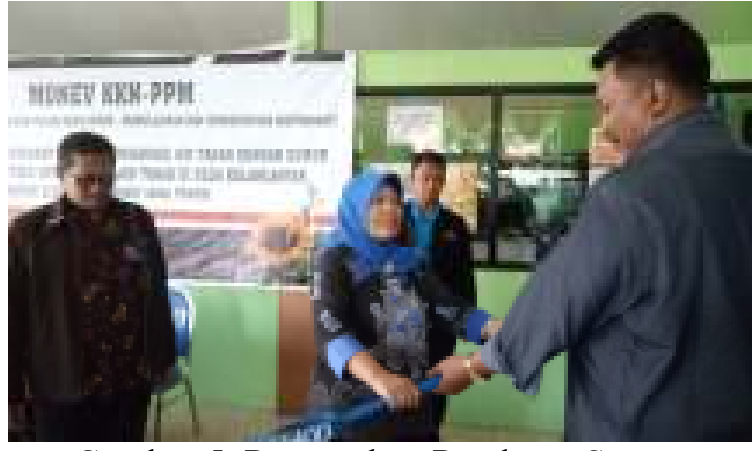

Gambar 5. Penyerahan Peralatan Secara Simbolik kepada Kepala Desa Kalanganyar

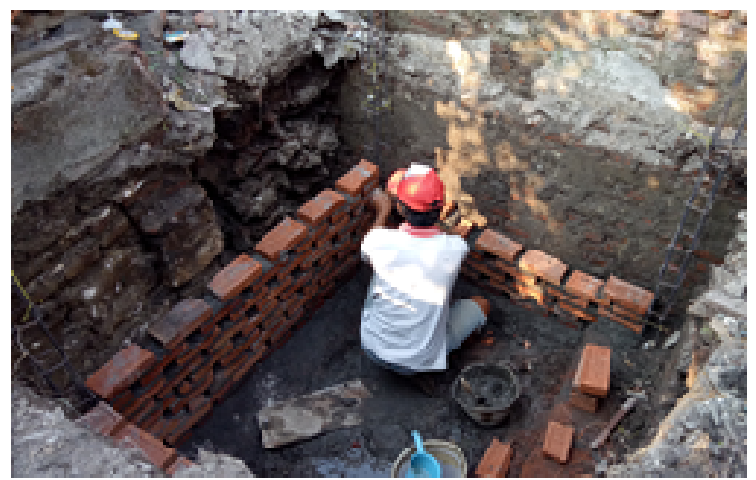

Gambar 6. Pemasangan Bata Sumur Resapan di Rumah Bapak Ulum RT 08

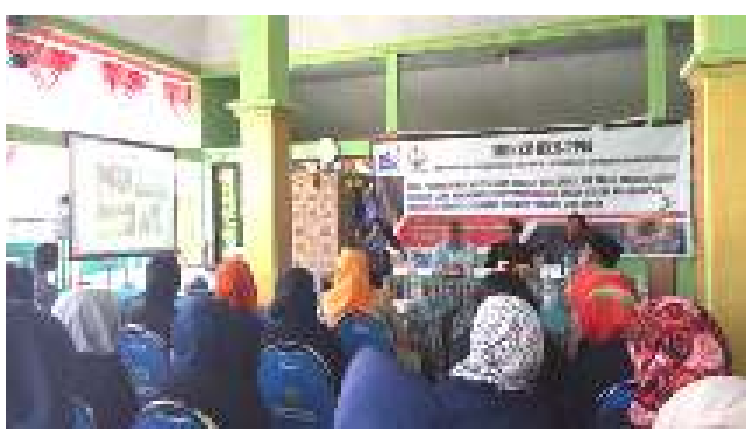

Gambar 7. Monev Internal Pelaksanaan Kegiatan KKN-PPM di Balai Desa Kalanganyar

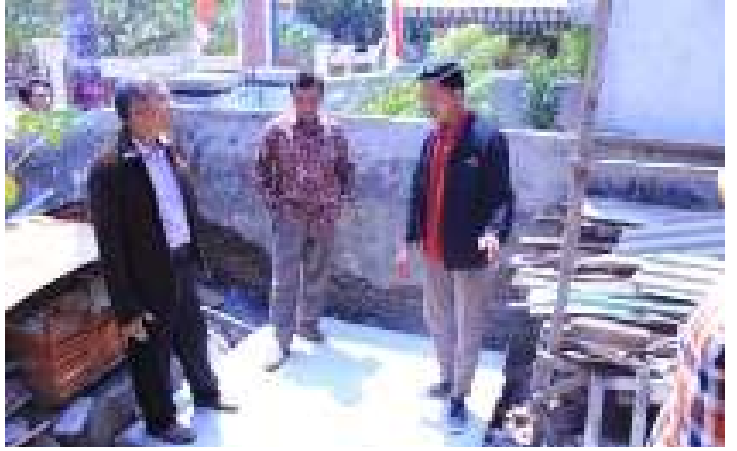

Gambar 8. Monev Internal pada Bangunan Sumur Resapan

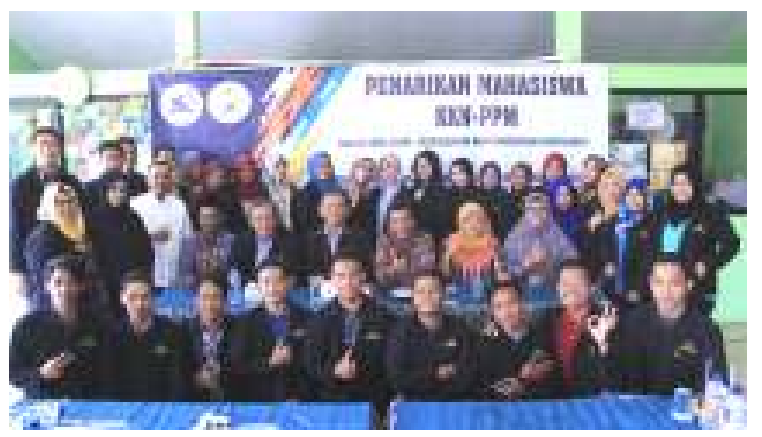

Gambar 9. Penarikan Mahasiswa KKN-PPM di Balai Desa Kalanganyar

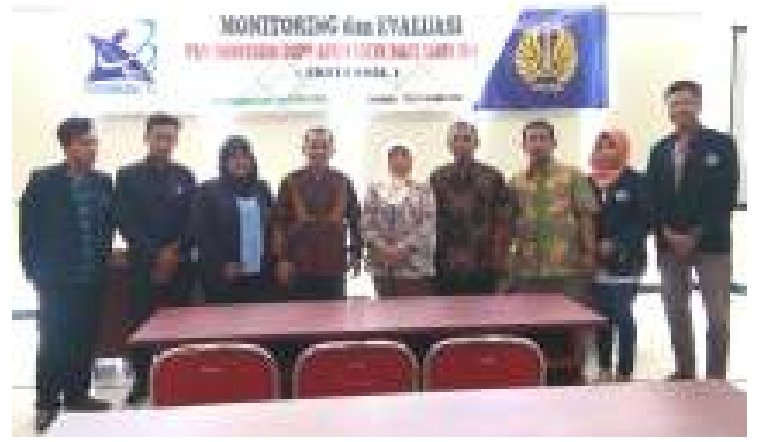

Gambar 10. Monev Eksternal Pelaksanaan Kegiataan KKN-PPM di Kampus UNESA Lidah Wetan

Hasil yang dicapai dalam kegiatan KKNPPM di Desa Kalanganyar Kecamatan Sedati Kabupaten Sidoarjo telah memenuhi target yang diharapkan. Sebelum adanya pelaksanaan KKN-PPM ini Desa Kalanganyar termasuk daerah yang mengalami keterbatasan air pada musim kemarau dan saat musim hujan tiba Desa Kalanganyar mengalami banjir. Setelah dilaksanakannya konservasi air tanah menggunakan TTG sumur resapan, dimana 
sumur resapan ini akan memberikan dampak berkurangnya limpasan permukaan. Air hujan yang semula jatuh ke atas permukaan genteng tidak langsung mengalir ke selokan atau halaman rumah tetapi dialirkan melalui seng terus ditampung ke dalam sumur resapan, sehingga air hujan tidak menyebar ke halaman atau selokan. Hal ini akan mengurangi terjadinya limpasan permukaan. Kegiatan KKN-PPM yang telah dilakukan memperoleh hasil yaitu:

1. Masyarakat dapat melakukan konservasi air tanah menggunakan TTG yang mudah dan memberikan hasil yang maksimal.

2. Lingkungan sekitar menjadi sehat dan nyaman karena apabila musim penghujan, banjir dapat teratasi.

3. Adanya perubahan perilaku masyarakat dalam melestarikan lingkungan khususnya konservasi air tanah menjadi sumber daya yang dapat dimanfaatkan pada saat musim kemarau tiba.

4. Kader lingkungan devisi mampu mengaplikasikan pembuatan dan penerapan sumur resapan pada RT lain di Desa Kalanganyar, sehingga akan ada sumur resapan yang akan dibangun pada RT lain.

5. Masyarakat Desa Kalanganyar sangat antusias mengikuti sosialisasi dan kegiatan KKN-PPM sehingga menginginkan adanya kegiatan lanjutan yang dapat diaplikasikan pada lingkungan tempat tinggal.

6. Masyarakat Desa Kalanganar Kecamatan Sedati Kabupaten Sidoarjo mempunyai keinginan untuk maju dan menambah wawasan lainnya

\section{KESIMPULAN}

Kesimpulan dari kegiatan KKN-PPM konservasi air tanah menggunakan sumur resapan di Desa Kalanganyar Kecamatan Sedati Kabupaten Sidoarjo Provinsi Jawa Timur adalah: 1. Masyarakat Desa Kalanganyar selama ini belum memanfaatkan air hujan pada musim penghujan yang menyebabkan limpasan air hujan menjadi banjir dan mengalami keterbatasan air pada saat musim kemarau, 2. Bertambahnya pengetahuan masyarakat Desa Kalanganyar tentang pelestarian lingkungan dan konservasi air tanah menggunakan sumur resapan, 3. Kegiatan KKN-PPM Desa Kalanganyar memberikan percontohan berupa bangunan sumur resapan pada Desa Kalanganyar untuk dijadikan percontohan konservasi air tanah pada Desa Kalanganyar.

\section{UCAPAN TERIMA KASIH}

Program KKN-PPM ini didanai oleh Direktorat Jenderal Penguatan Riset dan Pengembangan Kementerian Riset Teknologi dan Pendidikan Tinggi yang telah memberikan dana Pengabdian kepada Masyarakat dengan No. Kontrak 086.4/LPPM/5/2018 tanggal 26 Februari 2018, Universitas PGRI Adi Buana Surabaya atas dukungannya selama pelaksanaan program KKN-PPM. Pemerintah dan warga Desa Kalanganyar atas kontribusinya sehingga program KKN-PPM dapat terlaksana, serta mahasiswa KKN-PPM Desa Kalanganyar 2018 Universitas PGRI Adi Buana.

\section{REFERENSI}

Azwarman, (2015), Kajian Sumur Resapan Antisipasi Genangan Air Pada Perumahan Permata Kenali Untuk Pencegahan Banjir. Jurnal Ilmiah Universitas Batanghari Jambi.

Badan Standardisasi Nasional, (2017), Standar Nasional Indonesia (SNI) 8456: 2017 tentang Sumur dan Parit Resapan Air Hujan.

Badan Pusat Statistik Kabupaten Sidoarjo, (2018), Kecamatan Sedati dalam Angka.

Iriani K., Gunawan A., Besperi, (2013), Perencanaan Sumur Resapan Air Hujan untuk Konservasi Air Tanah di Daerah Permukiman (Studi Kasus di Perumahan RT. II, III, dan IV Perumnas Lingkar Timur Bengkulu), Jurnal Inersia Vol. 5, No. 1, Hal. 9-22. 
Lutjito, Manap, Wahyuni I., (2016), Penyuluhan Sumur Resapan Air Hujan pada Warga Pulokadang Canden Bantul, Proposal PPM Fakultas Teknik, Universitas Negeri Yogyakarta.

Nurhayati I., Widyastuti, S., Binawati, D.K., (2016), Pemberdayaan Masyarakat Desa Kalanganyar Sidoarjo melalui Pengolahan Limbah Kotoran Ikan menjadi Pupuk Organik Cair, Prosiding Seminar Tahunan Lingkungan Hidup, Universitas Brawijaya Malang, 145-153.

Sutrisno J., Pungut, Nurhayati I., Ratnawati R, (2018), Penerapan Biopori untuk Mengurangi Limpasan Air Hujan di Desa Kalanganyar Kecamatan Sedati Kabupaten Sidoarjo, Laporan Akhir Program Pengabdian kepada Masyarakat Program Studi Teknik Lingkungan Universitas PGRI Adi Buana Surabaya (data tidak terpublikasi).

Yuliyanti K., Indriati M. P., Frice L. D., (2017), Model Sumur Resapan dan Drainase Untuk Penanggulangan Banjir dengan Memanfaatkan Material Lokal. Jurnal Aksiologiya. Universitas Negeri Gorontalo. ISSN 2548-219. 